\title{
Continuous room decontamination technologies
}

\author{
David J. Weber MD, MPH ${ }^{\mathrm{a}, \mathrm{b}, *}$, William A. Rutala PhD, MPH ${ }^{\mathrm{b}}$, Emily E. Sickbert-Bennett MS, PhD ${ }^{\mathrm{a}, \mathrm{b}}$, \\ Hajime Kanamori MD, PhD, $\mathrm{MPH}^{\mathrm{c}}$, Deverick Anderson MD, MPH ${ }^{\mathrm{d}}$, CDC Prevention Epicenters Program \\ a Department of Hospital Epidemiology, University of North Carolina Hospitals, Chapel Hill, NC, USA \\ ${ }^{\mathrm{b}}$ Division of Infectious Diseases, University of North Carolina School of Medicine, Chapel Hill, NC, USA \\ ${ }^{c}$ Department of Infection Control and Laboratory Diagnostics, Tohoku University, Sendai, Japan \\ ${ }^{\mathrm{d}}$ Division of Infectious Diseases, Duke University School of Medicine, Durham, NC, USA
}

Key Words:

Disinfection

Self-disinfecting surfaces

\begin{abstract}
The contaminated surface environment in the rooms of hospitalized patients is an important risk factor for the colonization and infection of patients with multidrug-resistant pathogens. Improved terminal cleaning and disinfection have been demonstrated to reduce the incidence of health care-associated infections.

In the United States, hospitals generally perform daily cleaning and disinfection of patient rooms. However, cleaning and disinfection are limited by the presence of the patient in room (eg, current ultraviolet devices and hydrogen peroxide systems cannot be used) and the fact that after disinfection pathogenic bacteria rapidly recolonize surfaces and medical devices/equipment. For this reason, there has been great interest in developing methods of continuous room disinfection and/or "self-disinfecting" surfaces. This study will review the research on self-disinfecting surfaces (eg, copper-coated surfaces and persistent chemical disinfectants) and potential new room disinfection methods (eg, "blue light" and diluted hydrogen peroxide systems).
\end{abstract}

In 1991, Weinstein described the contribution of different sources of pathogens to health care-associated infections (HAIs). ${ }^{1}$ He noted that the majority of HAIs were due to the patient's endogenous flora but stated that $20 \%-25 \%$ were due to contamination of the environment or to other sources (eg, food, air, and personnel carriers). In the past decade, significant evidence has accumulated that contaminated environmental surfaces and noncritical patient care devices play an important role in the transmission of several key health care-associated pathogens, including methicillin-resistant Staphylococcus aureus (MRSA), vancomycin-resistant enterococci (VRE), Clostridioides difficile, Acinetobacter spp., and norovirus. ${ }^{2-8}$ Multiple studies have demonstrated that these pathogens can persist on hospital surfaces from days to weeks, frequently contaminate environmental surfaces in rooms of colonized or infected patients, may contaminate the gloves of health care personnel (HCP) or transiently colonize the hands of $\mathrm{HCP}$, leading to patient-to-patient transmission, and cause outbreaks in which environmental transmission likely played an important

\footnotetext{
* Address correspondence to David J. Weber, MD, MPH, University of North Carolina Hospitals, 2163 Bioinformatics, CB \#7030, Chapel Hill, NC 27599.

E-mail address: dweber@unch.unc.edu (D.J. Weber).

Conflicts of interest: D.J.W. and W.A.R. both serve as consultants for PDI.

Funding/support: Funding for this work was provided by the Centers for Disease Control and Prevention (CDC) Epicenters Program (U54CK000164).
}

role. ${ }^{2-8}$ Multiple studies have demonstrated that contact with the environment in a room housing a patient with a multidrug-resistant organism (MDRO) frequently leads to contamination of the gloves or hands of the HCP. ${ }^{9-11}$ In an important study, Kundrapu et al ${ }^{12}$ demonstrated that daily disinfection of high-touch surfaces in patient rooms with $C$ difficile and MRSA colonization reduced acquisition of the pathogens on hands after contacting high-touch surfaces and reduced hand contamination of HCP caring for patients.

The Centers for Disease Control and Prevention's (CDC's) Guideline for Disinfection and Sterilization in Healthcare Facilities recommends that environmental surfaces in hospital rooms be disinfected (or cleaned) on a regular basis (eg, daily, 3 times per week) and when surfaces are visibly soiled (category II recommendation). ${ }^{13}$ Studies of environmental cleaning during terminal disinfection of hospital rooms have demonstrated that the majority of surfaces are inadequately cleaned. ${ }^{14-16}$ Structured education and procedural interventions (eg, use of fluorescent markers to assess adequate cleaning with feedback to environmental service personnel) have been demonstrated to improve cleaning. ${ }^{15,16}$ However, despite the improvement shown by such programs, cleaning still remains inadequate. For this reason, multiple methods for providing continuous room disinfection have recently been developed (Table 1). ${ }^{17-21}$ Unfortunately, the "notouch" methods that are currently available for terminal room 
Table 1

Continuous room disinfection technologies

\begin{tabular}{l}
\hline Room disinfection technologies \\
\hline - Visible light (ie, "blue light," $400-470 \mathrm{~nm})$ \\
- Dilute hydrogen peroxide \\
- Far UV-C (207-222 nm) \\
"Self-disinfecting" surfaces \\
- Surface chemical disinfectants with persistence \\
- Quaternary ammonium compound-based agents \\
- Organosilane compounds \\
- Heavy metals: silver, copper \\
- Others \\
- Altered topography \\
- Antimicrobial peptides bound to surfaces \\
- Photoactivated surfaces (eg, TiO ${ }_{2}$, toluidine blue O, rose bengal) \\
- Anti-adhesive surfaces (eg, super hydrophobic surfaces) \\
- Attachment of bacteriophages to surfaces \\
- Surface coating with carbon nanotubes, graphene, or diamond-like carbons \\
\hline
\end{tabular}

disinfection, such as ultraviolet (UV) light devices and hydrogen peroxide systems, cannot be used with persons in the room and, therefore, are not suitable for continuous room disinfection if patients or $\mathrm{HCP}$ are present. ${ }^{21-24}$ This article will provide an update and expand on our previous review on "self-disinfecting" surfaces. The study is also focused on the recent progress in developing continuous room disinfection technologies. ${ }^{17}$

\section{CONTINUOUS ROOM DISINFECTION TECHNOLOGIES}

\section{Visible light (blue light)}

The electromagnetic spectrum includes visible light (ie, electromagnetic spectrum detected by the human eye), with a wavelength of $400-760 \mathrm{~nm}$, and UV light, with a spectrum of $100-400 \mathrm{~nm}$. UV light is further divided into UV-A light (315-400 nm), UV-B light (280-315 nm), and UV-C light (100-280 nm). UV-C light (254 nm) is germicidal, and room disinfection units producing UV-C light have been shown to effectively decontaminate intentionally contaminated surfaces and naturally contaminated room surfaces. ${ }^{21-24}$ Multiple clinical trials have demonstrated that UV-C room disinfection devices can reduce the likelihood that a patient subsequently admitted to the room that previously housed a patient colonized or infected with a multidrug-resistant pathogen will acquire the pathogen. ${ }^{21}$ Further, some studies have demonstrated a facility-wide decrease in multidrug-resistant pathogens. ${ }^{21}$

More recently, studies assessing the antimicrobial inactivation by visible light ("blue light") have been reviewed. ${ }^{25}$ Wang et al noted that blue light in the spectrum of $400-470 \mathrm{~nm}$ has demonstrated its intrinsic antimicrobial properties, resulting from the presence of endogenous photosensitizing chromophores in pathogenic microbes and, subsequently, its promise to counteract antibiotic resistance. The utility of 405-nm blue light for the inactivation of health care-associated pathogens and its potential role for environmental disinfection and infection control have been reviewed. ${ }^{25,26}$ In evaluating studies of blue light against health care-associated pathogens, it is important to note that the germicidal activity of both UV-C light and blue light depend on several factors, including pathogen susceptibility (spores are the most resistant), wavelength, light intensity, distance (energy falls off as the square of the distance), duration of exposure, organic load, and orientation to the light source. ${ }^{27-29}$

Halstead et $\mathrm{al}^{30}$ assessed the effectiveness of a light-emitting diode at $400 \mathrm{~nm}$ to kill 34 different bacterial strains that commonly cause HAIs, including Acinetobacter baumannii, Enterobacter cloacae, Pseudomonas aeruginosa, Escherichia coli, Klebsiella pneumoniae (including NDM-1), Staphylococcus aureus, and Enterococcus faecium. All planktonic-phase bacteria were susceptible to blue light, with the majority (71\%) demonstrating $\geq 5 \log _{10}$ decrease in viability after 15-30 minutes of exposure (54-108 J/cm²). More recently, Halstead et al $^{31}$ assessed the effectiveness of blue light at $405 \mathrm{~nm}$ against several strains of carbapenem-producing Enterobacteriaceae in 72-hour-old biofilms. All carbapenem-producing Enterobacteriaceae strains were susceptible to the blue light, with increasing reductions in seeding with increasing durations of exposure (ie, 5, 15, and 30 minutes). At 30 minutes, reductions in biofilm seeding of $>80 \%$ were observed for 11 of the 12 isolates. Barneck et al $^{32}$ studied the effectiveness of lightemitting diodes at $405 \mathrm{~nm}$ against $S$ aureus, Streptococcus pneumoniae, $E$ coli, and $P$ aeruginosa. Dose-dependent inactivation was observed for all species. At the highest radiant exposure levels (ie, $132 \mathrm{~J} / \mathrm{cm}^{2}$ ), reductions of $>5 \log _{10}$ were observed for bacteria strains tested. Wang et $\mathrm{al}^{33}$ demonstrated that blue light at $415 \mathrm{~nm}$ inactivated $>3 \log _{10}$ $P$ aeruginosa in 24- and 72-hour-old biofilms exposed for 72 minutes at $100 \mathrm{~mW} / \mathrm{cm}^{2}$. Blue light has been demonstrated to inactivate Candida albicans and other fungal species. ${ }^{34-36}$ In addition, blue light has been demonstrated to inactivate spores of Bacillus subtilis, $B$ megaterium, and $C$ difficile, although the dose required for inactivation of endospores is significantly higher compared with vegetative cells. ${ }^{37}$ Additional in vitro studies have been summarized. ${ }^{25}$

Several investigators have assessed blue light at $405 \mathrm{~nm}$ for continuous room disinfection of a "mock" hospital room ${ }^{38}$ or single-bed inpatient or outpatient rooms. ${ }^{39,40,41}$ The studies in occupied patient rooms were conducted with adherence to standard cleaning and/or disinfection protocols and with the blue light activated only during daylight hours (Table 2). These studies demonstrated a consistent 1 - to $2-\log _{10}$ reduction of surface bacteria. Surface bacterial levels increased when the lights were not operating. Importantly, Rutala et al was unable to demonstrate a reduction in $C$ difficile in a mock patient room with ceiling blue light units likely because the higher energy required to inactivate spores was not achieved. The studies in occupied rooms did not report any adverse patient events; however, there was no mention of a systematic assessment for adverse events.

In conclusion, studies of blue light demonstrated a consistent 1 - to $2-\log _{10}$ reduction of surface bacteria. Given that hospital room surfaces generally have $<2 \log _{10}$ bacteria, this may be sufficient inactivation to reduce the risk of acquisition/transmission of pathogenic bacteria to patients. However, no clinical trials of blue light have assessed whether their use can lead to a reduction in HAIs.

\section{Other room systems for continuous room disinfection}

\section{Dilute hydrogen peroxide}

As mentioned previously, hydrogen peroxide systems have demonstrated to inactivate $>4 \log _{10}$ on surfaces inoculated with MDRO placed in patient rooms. ${ }^{24}$ Clinical trials have shown when such units are used for terminal disinfection in rooms previously occupied by a patient colonized or infected with an MDRO, these systems may reduce the risk of a subsequent patient admitted to room developing colonization or an infection with the MDRO. ${ }^{44}$ However, because of the high level of hydrogen peroxide achieved by these systems, neither the patients nor the HCP can occupy the room. Recently, systems have been developed that produce low levels of hydrogen peroxide that can be used in an occupied room. Rutala et $\mathrm{al}^{45}$ tested one such system located outside of a model patient room but were unable to demonstrate inactivation of several bacteria (ie, MRSA, VRE, multidrug resistance-A baumannii) inoculated onto test surfaces and placed in the room. To our knowledge, no clinical trials of dilute hydrogen peroxide systems have been published to date in the peer-reviewed literature. 
Table 2

Effectiveness of "blue light" at $405 \mathrm{~nm}$ to decontaminated patient rooms

\begin{tabular}{|c|c|c|c|c|}
\hline Location & Operating hours & $\begin{array}{l}\text { Standard EVS } \\
\text { cleaning }\end{array}$ & Results & Author, year \\
\hline Orthopedic OR & - & Yes & $\begin{array}{l}81 \%(P=.017) \text { reduction in CFU in OR test room after } \\
\text { installation of visible-light system, and } 49 \% \\
(P=.015) \text { compared with a control OR room. SSIs in } \\
\text { treated room decreased from } 1.4 \% \text { to } 0.4 \%(P=.029)\end{array}$ & Murrell, $2019^{41}$ \\
\hline Mock patient room & $24 \mathrm{~h}$ & No & $\begin{array}{l}90 \% \text { reduction of MRSA }(10 \mathrm{~h}), \operatorname{VRE}(15 \mathrm{~h}), \mathrm{MDR}-A c i- \\
\text { netobacter baumannii }(15 \mathrm{~h}), \mathrm{C} \text { difficile (NA) }\end{array}$ & Rutala, $2018^{38}$ \\
\hline Burn room, unoccupied & $24 \mathrm{~h}$ & Yes & $\sim 90 \%$ reduction of surface bacterial levels & Maclean, $2010^{39}$ \\
\hline $\begin{array}{l}\text { Burn room, occupied by } \\
\text { MRSA patient }\end{array}$ & $8 \mathrm{AM}$ to $10: 15 \mathrm{PM}$ & Yes & $\begin{array}{l}56 \%-85 \% \text { reductions surface bacterial levels and } 56 \% \\
\text { reduction in presumptive Staphylococcus aureus }\end{array}$ & Maclean, $2010^{39}$ \\
\hline $\begin{array}{l}\text { Burn unit, occupied } \\
\text { inpatient room }\end{array}$ & $14 \mathrm{~h}$ & Yes & $27 \%-75 \%$ reduction in surface bacterial levels & Bache, $2012^{42}$ \\
\hline $\begin{array}{l}\text { Burn unit, occupied } \\
\text { outpatient room }\end{array}$ & While clinic operating $(8 \mathrm{~h})$ & Yes & $61 \%$ reduction in surface bacterial levels & Bache, $2012^{42}$ \\
\hline $\begin{array}{l}\text { ICU, occupied inpatient } \\
\text { room }\end{array}$ & $7: 30 \mathrm{AM}$ to $10 \mathrm{PM}$ & Yes & Reductions of surface bacterial levels of up to $67 \%$ & Maclean, $2013^{43}$ \\
\hline $\begin{array}{l}\text { Burn unit, occupied } \\
\text { inpatient rooms }\end{array}$ & $8 \mathrm{AM}$ to $10 \mathrm{PM}$ & Yes & $\begin{array}{l}22 \%-86 \% \text { reduction in mean number of surface } \\
\text { bacteria }\end{array}$ & Bache, $2018^{40}$ \\
\hline
\end{tabular}

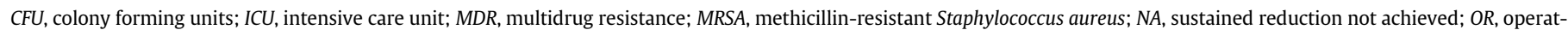
ing room; SSIs, surgical site infections; VRE, vancomycin-resistant enterococci.

\section{Far UV-C light}

Although far UV-C light (ie, 207-222 nm) has not been shown to induce mammalian skin damage, ${ }^{46}$ it has efficiently inactivated bacteria such as $S$ aureus ${ }^{47}$ and aerosolized the H1N1 influenza virus. ${ }^{48}$ To our knowledge, no clinical trials of far UV-C have been published.

\section{SELF-DISINFECTING SURFACES}

\section{Background}

In recent years, a number of different technologies have been developed in an attempt to devise self-disinfecting surfaces (Table 1). ${ }^{17-19,49-54}$ Such surfaces have also been called "self-sanitizing," and because microbial inactivation requires direct contact with the surface, the term "contact killing" has also been used. This section will review the most promising self-disinfecting" surface technologies. The advantages and disadvantages of currently proposed selfdisinfecting surfaces are summarized in Table 3.

Table 3

Advantages and limitations of currently proposed self-disinfecting surfaces in hospital rooms

\begin{tabular}{l}
\hline Advantages \\
\hline - Provides continuous disinfection of environmental surfaces \\
- Does not depend on adequacy of cleaning/disinfection by environmental \\
service staff \\
- Broad-spectrum antimicrobial activity \\
- Very low or no toxicity to humans \\
\hline Current limitations
\end{tabular}

- Impossible to impregnate or to coat all possible room surfaces and medical devices used in a hospital room

- Efficacy of self-disinfecting surfaces to decrease HAIs has not been conclusively demonstrated in clinical trials (best data are for copper but clinical trials have had mixed results)

- Possible development of resistance by microbes to the self-disinfecting method (eg, microbial resistance to silver and copper have been demonstrated).

- In general, modest reductions in surface contamination (ie, $1-2 \log _{10}$ reductions) demonstrated

- Durability with repeated cycles of cleaning and disinfection not yet evaluated (best data are for copper but even with copper, data on durability are limited)

- Cost of purchasing and installing self-disinfecting surfaces is not available

- Cost-effectiveness of self-disinfecting surfaces has not been demonstrated

NOTE: Adapted from Weber DJ, Rutala WA. Am J Infect Control 2013;41(Suppl):31-5. ${ }^{18}$ HAIs, health care-associated infections.

\section{Surface disinfectants with persistence}

\section{Quaternary ammonium compounds}

Quaternary ammonium compounds are widely used for low-level disinfection of surfaces in health care facilities. ${ }^{55,56}$ In a study of disinfection of computer keyboards, Rutala et $\mathrm{al}^{57}$ demonstrated that all 3 tested quaternary ammonium compounds showed excellent sustained activity against VRE, and antimicrobial activity was maintained over the entire 48-hour test period. Similarly, all 3 quaternary ammonium compounds demonstrated sustained activity against $P$ aeruginosa, but at a level less than that for VRE. ${ }^{57}$ However, the germicidal activity of the quaternary ammonium compounds was lost by wiping the treated areas with a soapy solution. ${ }^{57}$ More recently, Tamimi et $\mathrm{al}^{58}$ demonstrated that a formulation of a quaternary ammonium organosilane compound that binds to surfaces produced long-term residual disinfecting activity. In this study, the average bacterial count on all treated surfaces was reduced by $>99 \%$ for at least 8 weeks after treatment. Overall, average levels of bacteria never returned to those observed before treatment even after 15 weeks. Antibiotic-resistant bacteria were found on $25 \%$ of the sites tested before treatment, but were isolated at only 1 site during the 15 weeks after treatment. Recently, Rutala et al investigated the persistent antimicrobial activity of a novel quaternary ammonium disinfectant. Surfaces were treated with the novel disinfectant, allowed to dry, and then abraded using a standardized abrasion machine under multiple alternating wet and dry wipe conditions interspersed with 6 re-inoculations. After 24 hours, the surface was re-inoculated a final time and the ability of the disinfectant to kill $>99.9 \%$ of test microbes within 5 minutes measured on 3 test surfaces (ie, glass, Formica, and stainless steel). At the 24-hour time point, the novel disinfectant achieved a 3- to $5-\log _{10}$ reduction in 5 minutes of $S$ aureus, VRE, Candida auris, and carbapenem-resistant $E$ coli. ${ }^{59}$ A 1.5 - to $2.1-\log _{10}$ kill was noted for carbapenem-resistant Enterobacter sp and Klebsiella pneumoniae. Schmidt et al compared a "trial" disinfectant (70\% ethanol with $<1 \%$ mixed quaternary ammonium chloride plus other proprietary agents) applied to patient bed rails and 2 commonly used hospital disinfectants (Cavicide, Metrex, Orange, CA; Virex II 256, Diversey, Charlotte, $\mathrm{NC}){ }^{60}$ The trial disinfectant was found superior to the other agents over a 24-hour period. However, the difference between the trial disinfectant and the comparators was $<1 \log _{10}$.

Although only limited data on novel quaternary ammonium compounds exists, they show promise for providing continuously active 
disinfection. Further studies and clinical trials are warranted to assess efficacy and durability.

\section{Organosilanes}

Organosilane compounds are comprised by a surfactant plus an antimicrobial substance such as a quaternary ammonium moiety. ${ }^{19}$ These compounds are designed to minimize bacterial contamination of surfaces by maintaining their antimicrobial activity on surfaces for weeks to months. As noted by Boyce, ${ }^{19}$ the ability of these compounds to prevent contamination of surfaces for prolonged periods of time is unclear.

\section{Heavy metals}

\section{Background}

Elements that form positive ions (ie, cations) by losing electrons during chemical reactions are termed metals. Approximately 65 elements possess these qualities, have a specific gravity $>5$, are considered the "heavy" metals. Although most metals are either insoluble or extremely rare, and their effects on biologic systems are of minor importance, $>30$ heavy metals may potentially interact with microorganisms. ${ }^{18,61}$ Heavy metals influence microorganisms by affecting their growth, morphology, and biochemical activities. Many metals are essential to life (eg, sodium [Na], potassium [K], calcium [Ca], and iron [Fe]). Toxicity is a result of blocking of functional groups of important molecules (eg, enzymes, polynucleotides, transport systems for essential nutrients, and ions), displacement of or substitution of essential ions from cellular sites, denaturation and inactivation of enzymes, and disruption of cellular and organelle membrane integrity. Virtually all metals, whether essential or nonessential, can exhibit toxicity above certain threshold concentrations, which for highly toxic metals may be extremely low.

Resistance to metals has been described in microbes and is mediated by multiple mechanisms. First, metal ions may be converted into less toxic forms by the action of enzymes, oxidases, and reductases. Second, sequestration and binding to toxic metals in the cell wall or within the cell may occur. Third, altered uptake pathways may result in blocking of cellular uptake. Finally, an enhanced, highly specific efflux system may decrease intracellular concentrations. As with antibiotic resistance, bacterial resistance to the toxic effects of heavy metals may be plasmid mediated. The most commonly used metals for treatment of human illnesses have been silver, copper, and mercury. In this section, we will focus on studies that have assessed the use of silver, copper, and titanium dioxide for surface disinfection.

\section{Silver}

Silver compounds are currently used for a variety of medical purposes such as topical antisepsis (eg, silver nitrate and silver sulfadiazine) and antimicrobial-resistant indwelling devices (eg, central venous catheters). ${ }^{18,54}$ Silver ions have the highest level of antimicrobial activity of all the heavy metals. ${ }^{61,62}$ Although many mechanisms for silver's bactericidal activity have been proposed, the observed bactericidal efficacy of silver is thought to be through the strong binding with disulfide (S-S) and sulfhydryl (-SH) groups found in the proteins of microbial cell walls. ${ }^{62}$ Through this binding event, normal metabolic processes are disrupted, leading to cell death. Both intrinsic and acquired silver resistance have been well described in bacteria. ${ }^{62,63}$

Silver may be added to polymers to confer antimicrobial activity and has been incorporated into consumer products such as toys, telephones, and infant pacifiers. ${ }^{61}$ In health care, products incorporating silver have included clothing (eg, scrubs), fabrics (eg, sheets), and surfaces. ${ }^{18,52,61,64}$ One product (Surfacine, Surfacine Development Company, Tyngsborough, MA) has been assessed for use as a selfdisinfecting surface in hospitals. ${ }^{65}$ It incorporates a water-soluble antimicrobial compound (silver iodide) in a surface-immobilized coating (a modified poly-hexamethlyenebiguanide) that is capable of chemical recognition and interaction with the lipid bilayer of the bacterial outer cell membrane by electrostatic attraction. Microorganisms contacting the coating accumulate silver until the toxicity threshold is exceeded. Surfacine can be applied to inanimate surfaces by dipping, brushing, or spraying without prior surface treatment. Surfaces to which this agent had been applied have been shown to kill 3.3-4.3 $\log _{10} S$ aureus and 2.2-4.8 $\log _{10} P$ aeruginosa hours after application of Surfacine. ${ }^{66}$ In addition, a $>3 \log _{10}$ kill of MRSA and VRE was also achieved. ${ }^{66}$ Residual activity of Surfacine against VRE has been shown for 13 days. ${ }^{65}$ The antibacterial effect of a silver/zinc zeolite ceramic coating on stainless steel has been demonstrated by challenge with $S$ aureus, E coli, and $P$ aeruginosa, but to date there are no studies of actual hospital surfaces coated with a silver/zinc zeolite. ${ }^{67,68}$ In addition, we are unaware of any published studies assessing the ability of silver-coated or -impregnated surfaces to reduce the microbial contamination on environmental surfaces in actual hospital rooms or to decrease the incidence of HAIs.

\section{Copper}

The use of copper as an antimicrobial on surfaces has been reviewed. ${ }^{17-19,69-77}$ Copper is an essential trace element in most living organisms, and $>30$ types of copper-containing proteins have been described. ${ }^{69-71}$ The use of copper by humans dates back to the 5 th and 6 th millennia BC. ${ }^{18,69,70}$ Ancient civilizations used copper or copper compounds to prevent the growth of barnacles on the hulls of ships and as a medicinal agent. In the 19th and 20th centuries, inorganic copper preparations were used to treat chronic adenitis, eczema, impetigo, tuberculous infections, and syphilis. ${ }^{70}$ The cause of bacterial cell death to exposure to copper may relate to its ability to accept and donate single electrons leading to the generation of reactive oxygen species, resulting is cell lysis. ${ }^{18,19,52,61}$ In health care facilities, the most well-studied use of copper has been as a self-disinfecting surface; however, many other uses have been studied, including copper-containing paints, fabrics, hand rubs, microfiber cleaning cloths, pens, and fins within air-conditioning units. ${ }^{18,61}$

Multiple studies have assessed the contact killing of microbes by copper surfaces. ${ }^{18,70}$ Contact with copper has been demonstrated to kill a variety of health care-associated pathogens, including $S$ aureus (including MRSA), enterococcus, $E$ coli, K pneumoniae, A baumannii, $P$ aeruginosa, and Mycobacterium tuberculosis. ${ }^{70-72}$ In general, contact killing of vegetative bacteria and fungi occurs rapidly with $>6 \log _{10}$ inactivation per hour. Spores (eg, $C$ difficile) are inactivated more slowly, but $>3 \log _{10}$ are inactivated within 24 hours. ${ }^{18}$ According to Grass et al, $^{70}$ a few general principles can be drawn from these in vitro studies: higher copper content of alloys, higher temperature, and higher relative humidity increase the efficacy of killing. Treatments that lowered corrosion rates (eg, application of corrosion inhibitors or a thick copper oxide layer) lowered the antimicrobial effectiveness of copper surfaces. As with silver, microbes may exhibit resistance to copper.

Multiple studies of copper-coated surfaces or devices have been conducted in the health care setting comparing the level and frequency of surface contamination with control surfaces. ${ }^{74}$ Studies have either used concurrent non-copper-coated control surfaces or a crossover design. Muller et $\mathrm{al}^{51}$ reported that 5 of 7 copper studies of copper-coated surfaces or fabrics reviewed demonstrated a significant reduction in quantitative bacterial contamination of $<1 \log _{10}$ (range, $<1-2 \log _{10}$ ).Limitations of the studies noted by Muller et $\mathrm{al}^{51}$ included lack of blinding, lack of randomization, and, in general, failure to measure potential confounding factors (eg, hand hygiene compliance and effectiveness of cleaning by environmental services) or report any patient-level data. Similar to previous studies, 2 additional recent studies demonstrated significant reductions of microbial 
contamination on copper-coated surfaces compared with control surfaces of 1-2 $\log _{10}{ }^{76,77}$ Importantly, resistance to copper has been described in microbes.

Three clinical trials have been published in the English literature that assessed the effectiveness of copper-coated surfaces to reduce HAIs (Table 4). ${ }^{77-79}$ Of these 3 trials, 2 reported that the intervention arm (ie, copper) had a decreased incidence of HAIs, and 1 trial reported no significant reduction in HAIs. Importantly, none of these trials assessed the effectiveness of environmental cleaning and disinfection using fluorescent dye or adenosine triphosphate measurements, and 1 of the trials did not assess compliance with hand hygiene. Although Salgado et al described their trial as a randomized clinical trial, Muller et al described this study as "low-quality evidence due to inappropriate randomization and lack of blinding." ${ }^{51}$ An additional clinical trial has been published in the Spanish literature, reporting no differences in the frequency of nosocomial infections as well as no differences in the rates of ventilator-associated pneumonia, catheter-associated urinary tract infections, or central line-associated bloodstream infections. ${ }^{81}$ However, this study was limited by its failure to achieve its intended sample size.

The potential advantages and limitations/deficiencies in the scientific literature of studies assessing the efficacy of copper to reduce surface contamination and HAIs in hospital rooms have been summarized. ${ }^{74}$ In summary, copper-coated surfaces have demonstrated the ability to inactivate many key pathogens associated with HAIs. Multiple studies have demonstrated that copper-coated surfaces can reduce the level of contamination on room surfaces by $1-2 \log _{10}$. To date, clinical trials have reported only rare adverse reactions related to contact with a copper-coated surface, and only a limited number of clinical trials have been published assessing whether copper-coated surfaces reduce the incidence of HAIs. Published studies have not yet shown copper-coated surfaces uniformly reducing HAIs. Furthermore, these published studies have design flaws, including failure to use a randomized design and failure to account for all possible confounding variables (eg, hand hygiene compliance and cleaning effectiveness). Thus, the use of coppercoated surfaces to provide continuous room disinfection is promising, but additional carefully designed and appropriately powered studies are required before this technology should be routinely adopted to prevent HAIs.

\section{Light-activated photosensitizers: Titanium dioxide}

Light-activated photosensitizers, such as nanosized titanium dioxide (TiO2) applied to surfaces using UV-A or visible light to generate reactive oxygen species that can disinfect surfaces, have been evaluated. ${ }^{19,52,82,83}$ Titanium dioxide compounds doped with other metals (eg, silver $[\mathrm{Ag}]$ and zinc [Zn]) have been assessed for antimicrobial activity. Such compounds have demonstrated inactivation of pathogens (ie, viruses, bacteria, and fungi) associated with HAIs, however the rate of decrease depends on thin film composition and the illumination used. ${ }^{49,54}$ Kim et al performed a prospective cohort study in a medical intensive care unit in which a titanium dioxide photocatalyst was applied to high-touch surfaces and walls. ${ }^{83}$ In this before-after study, there was a significant decrease in the rate of MRSA acquisition after application of the photocatalyst (hazard ratio, $0.37 ; P=.04$ ) but a decrease in VRE or multidrug-resistant $A$ baumannii was not observed. ${ }^{84}$ The risk of developing hospitalacquired pneumonia during the intervention compared to baseline period was $0.46(P=.03) .{ }^{84}$ In a before-after study conducted in a long-term care facility, Pulliam ${ }^{83}$ coated all available surfaces with a titanium dioxide compound and reported a 30\% decrease in HAIs $(P=.02) .{ }^{83}$ However, a prospective (before-after) study by de Jong et $\mathrm{al}^{84}$ reported that a titanium dioxide coating on all surfaces in an intensive care unit had no effect on the microbial colonization of surfaces.

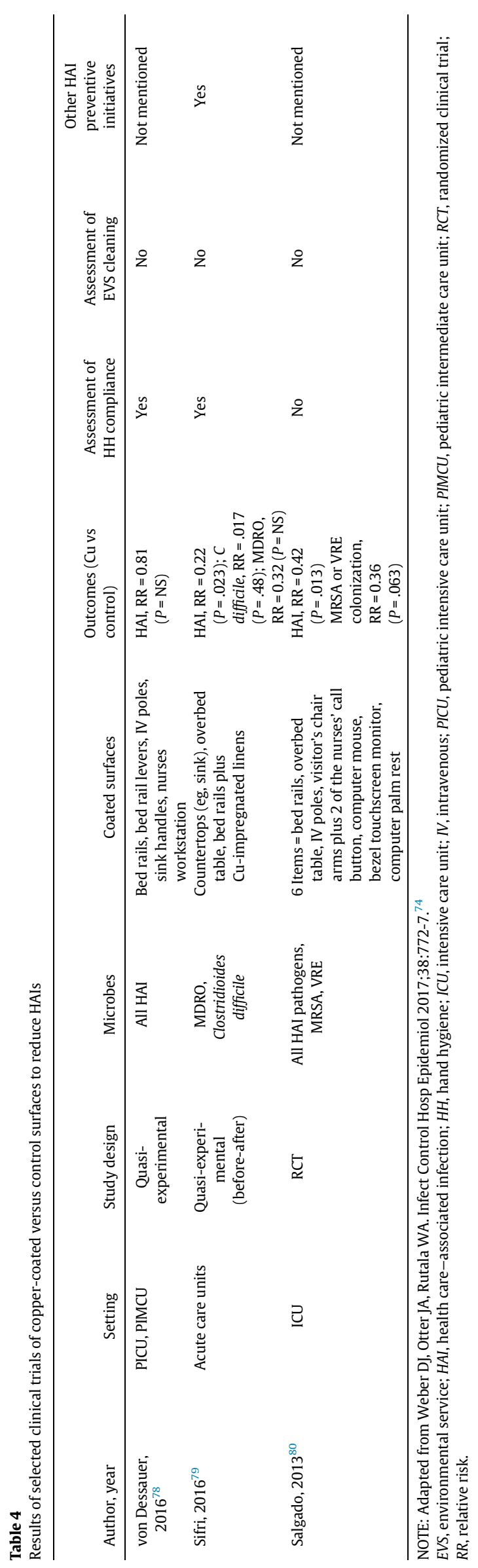


Even if properly manufactured, the slow action time of the lightactivated photosensitizer, ion-doped, $\mathrm{TiO} 2$ nanoparticles would allow it only to be a supplement to conventional surface disinfection. ${ }^{84}$

\section{References}

1. Weinstein RA. Epidemiology and control of nosocomial infections in adult intensive care units. Am J Med 1991;91:179-84.

2. Boyce JM. Environmental contamination makes an important contribution to hospital infection. J Hosp Infect 2007;65(Suppl 2)):50-4.

3. Weber DJ, Rutala WA, Miller MB, Huslage K, Sickbert-Bennett E. Role of hospital surfaces in the transmission of emerging health care-associated pathogens: norovirus, Clostridium difficile, and Acinetobacter species. Am J Infect Control 2010;38 (Suppl 1):25-33.

4. Otter JA, Yezli S, French GL. The role played by contaminated surfaces in the transmission of nosocomial pathogens. Infect Control Hosp Epidemiol 2011;32:687-99.

5. Otter JA, Yezli S, Salkeld JA, French GL. Evidence that contaminated surfaces contribute to the transmission of hospital pathogens and an overview of strategies to address contaminated surfaces in hospital settings. Am J Infect Control 2013;41 (Suppl 5):6-11

6. Weber DJ, Anderson D, Rutala WA. The role of the surface environment in healthcare-associated infections. Curr Opin Infect Dis 2013;26:338-44.

7. Siani H, Maillard JY. Best practice in healthcare environment decontamination. Eur J Clin Microbiol Infect Dis 2015;34:1-11.

8. Rutala WA, Weber DJ. Best practices for disinfection of noncritical environmental surfaces and equipment in health care facilities: a bundle approach. Am J Infect Control 2019;47(Suppl):A96-105.

9. Hayden MK, Blom DW, Lyle EA, Moore CG, Weinstein RA. Risk of hand or glove contamination after contact with patients colonized with vancomycin-resistant enterococcus or the colonized patients' environment. Infect Control Hosp Epidemiol 2008;29:149-54.

10. Stiefel U, Cadnum JL, Eckstein BC, Guerrero DM, Tima MA, Donskey CJ. Contamination of hands with methicillin-resistant Staphylococcus aureus after contact with environmental surfaces and after contact with the skin of colonized patients. Infect Control Hosp Epidemiol 2011;32:185-7.

11. Morgan DJ, Rogawski E, Thom KA, Johnson JK, Perencevich EN, Shardell M, et al. Transfer of multidrug-resistant bacteria to healthcare workers' gloves and gowns after patient contact increases with environmental contamination. Crit Care Med 2012;40:1045-51.

12. Kundrapu S, Sunkesula V, Jury LA, Sitzlar BM, Donskey CJ. Daily disinfection of high-touch surfaces in isolation rooms to reduce contamination of healthcare workers' hands. Infect Control Hosp Epidemiol 2012;33:1039-42.

13. Rutala WA, Weber DJ. Guideline for disinfection and sterilization in healthcare facilities, 2008. Available from: https://www.cdc.gov/infectioncontrol/guidelines/ disinfection/index.html. Accessed March 1, 2019.

14. Carling PC. Optimizing health care environmental hygiene. Infect Dis Clin North Am 2016;30:639-60.

15. Carling PC, Parry MF, Bruno-Murtha LA, Dick B. Improving environmental hygiene in 27 intensive care units to decrease multidrug-resistant bacterial transmission. Crit Care Med 2010;38:1054-9.

16. Carling PC, Parry MM, Rupp ME, Po JL, Dick B, von Beheren S. Improving cleaning of the environment surrounding patients in 36 acute care hospitals. Infect Control Hosp Epidemiol 2008;29:1035-41.

17. Weber DJ, Rutala WA. Self-disinfecting surfaces. Infect Control Hosp Epidemiol 2012;33:10-3.

18. Weber DJ, Rutala WA. Self-disinfecting surfaces: review of current methodologies and future prospects. Am J Infect Control 2013;41(Suppl 5):S31-5.

19. Boyce JM. Modern technologies for improving cleaning and disinfection of environmental surfaces in hospitals. Antimicrob Resist Infect Control 2016;5:10.

20. Doll M, Stevens M, Bearman G. Environmental cleaning and disinfection of patient areas. Int J Infect Dis 2018;67:52-7.

21. Weber DJ, Kanamori H, Rutala WA. 'No touch' technologies for environmental decontamination: focus on ultraviolet devices and hydrogen peroxide systems. Curr Opin Infect Dis 2016;29:424-31.

22. Otter JA, Yezli S, Perl TM, Barbut F, French GL. The role of 'no-touch' automated room disinfection systems in infection prevention and control. J Hosp Infect 2013;83:1-13.

23. Rutala WA, Weber DJ. Disinfectants used for environmental disinfection and new room decontamination technology. Am J Infect Control 2013;41(Suppl 5):36-41.

24. Weber DJ, Rutala WA, Anderson DJ, Chen LF, Sickbert-Bennett EE, Boyce JM. Effectiveness of ultraviolet devices and hydrogen peroxide systems for terminal room decontamination: Focus on clinical trials. Am J Infect Control 2016;44(Suppl 5): e77-84.

25. Wang Y, Wang Y, Wang Y, Murray CK, Hamblin MR, Hooper DC, et al. Antimicrobial blue light inactivation of pathogenic microbes: state of the art. Drug Resist Updat 2017;33-35:1-22.

26. Maclean M, McKenzie K, Anderson JG, Gettinby G, MacGregor SJ. 405 nm light technology for the inactivation of pathogens and its potential role for environmental disinfection and infection control. J Hosp Infect 2014;88:1-11.

27. Cadnum JL, Tomas ME, Sankar T, Jencson A, Mathew JI, Kundrapu S, et al. Effect of variation in test methods on performance of ultraviolet-C radiation room decontamination. Infect Control Hosp Epidemiol 2016;37:555-60.
28. Tande BM, Pringle TA, Rutala WA, Gergen MF, Weber DJ. Understanding the effect of ultraviolet light intensity on disinfection performance through the use of ultraviolet measurements and simulation. Infect Control Hosp Epidemiol 2018;39: 1122-4.

29. Cadnum JL, Jencson AL, Gestrich SA, Livingston SH, Karaman BA, Benner KJ, et al Infect Control Hosp Epidemiol 2019;40:158-63.

30. Halstead FD, Thwaite JE, Burt R, Laws TR, Raguse M, Moeller R, et al. Antibacterial activity of blue light against nosocomial wound pathogens growing planktonically and as mature biofilms. Appl Environ Microbiol 2016;82:4006-16.

31. Halstead FD, Ahmed Z, Bishop JRB, Oppenheim BA. The potential of visible blue light $(405 \mathrm{~nm})$ as a novel decontamination strategy for carbapenemase-producing enterobacteriaceae (CPE). Antimicrob Resist Infect Control 2019;8:14.

32. Barneck MD, Rhodes NLR, de la Presa M, Allen JP, Poursaid AE, Nourian MM, et al. Violet 405-nm light: a novel therapeutic agent against common pathogenic bacteria. J Surg Res 2016;206:316-24.

33. Wang Y, Wu X, Chen J, Amin R, Lu M, Bhayana B, Zhao J, et al. Antimicrobial blue light inactivation of Gram-negative pathogens in biofilms: in vitro and in vivo studies. J Infect Dis 2016;213:1380-7.

34. Zhang Y, Zhu Y, Chen J, Wang Y, Sherwood ME, Murray CK, et al. Antimicrobial blue light inactivation of Candida albicans: in vitro and in vivo studies. Virulence 2016;7:536-45.

35. Durantini EN. New insights into the antimicrobial blue light inactivation of Candida albicans. Virulence 2016;7:493-4.

36. Dai T, Hamblin MR. Visible blue light is capable of inactivating Candida albicans and other fungal species. Photomed Laser Surg 2017;35:345-6.

37. Maclean M, Murdoch LE, MacGregor SJ, Anderson JG. Sporicidal effects of highintensity $405 \mathrm{~nm}$ visible light on endospore-forming bacteria. Photochem Photobiol 2013;89:120-6.

38. Rutala WA, Kanamori H, Gergen MF, Sickbert-Bennett EE, Sexton DJ, Anderson DJ, et al. Antimicrobial activity of a continuous visible light disinfection system. Infect Control Hosp Epidemiol 2018;39:1250-3.

39. Maclean M, Macgregor SJ, Anderson JG, Woolsey GA, Coia JE, Hamilton K, et al. Environmental decontamination of a hospital isolation room using high-intensity narrow-spectrum light. J Hosp Infect 2010;76:247-51.

40. Bache SE, Maclean M, Gettinby G, Anderson JG, MacGregor SJ, Taggart I. Universal decontamination of hospital surfaces in an occupied inpatient room with a continuous $405 \mathrm{~nm}$ light source. J Hosp Infect 2018;98:67-73.

41. Murrell LJ, Hamilton EK, Johnson HB, Spencer M. Influence of a visible-light continuous environmental disinfection system on microbial contamination and surgical site infections in an orthopedic operating room. Am J Infect Control 2019 Jan 10. https://doi.org/10.1016/j.ajic.2018.12.002, [Epub ahead of print].

42. Bache SE, Maclean M, MacGregor SJ, Anderson JG, Gettinby G, Coia JE, et al. Clinical studies of the high-intensity narrow-spectrum light environmental decontamination system (HINS-light EDS), for continuous disinfection in the burn unit inpatient and outpatient settings. Burns 2012;38:69-76.

43. Maclean M, Booth MG, Anderson JG, MacGregor SJ, Woolsey GA, Coia JE, et al. Continuous decontamination of an intensive care isolation room during patient occupancy using $405 \mathrm{~nm}$ light technology. J Infect Prevent 2013;14:176-81.

44. Rutala WA, Kanamori H, Gergen M, Sickbert-Bennett E, Anderson D, Weber DJ. Application of dilute hydrogen peroxide gas technology for continuous room decontamination of multidrug-resistant organisms: negative results from a preliminary study. Open Forum Infect Dis 2017;4(Suppl 1):185-6.

45. Buonanno M, Ponnaiya B, Welch D, Stanislauskas M, Randers-Pehrson G, Smilenov L, et al. Germicidal efficacy and mammalian skin safety of 222-nm UV light. Radiat Res 2017;187:483-91.

46. Buonanno M, Randers-Pehrson G, Bigelow AW, Trivedi S, Lowy FD, Spotnitz HM, et al. 207-nm UV light - a promising tool for safe low-cost reduction of surgical site infections. I: In-vitro safety studies. PLoS One 2013;8:e76968.

47. Welch D, Buonanno M, Grilj V, Shuryak I, Crickmore C, Bigelow AW, et al. Far-UVC light: a new tool to control the spread of airborne-mediated microbial diseases. Sci Rep 2018;8:2752

48. Glinel K, Thebault P, Humblot V, Pradier CM, Jouenne T. Antibacterial surfaces developed from bio-inspired approaches. Acta Biomater 2012;8:1670-84.

49. Villapún VM, Dover LG, Cross A, González S. Antibacterial metallic touch surfaces. Materials (Basel) 2016;9:736.

50. Kaur R, Liu S. Antibacterial surface design-contact time. Progress on Surface Science 2016;91:136-53.

51. Muller MP, MacDougall C, Lim M. Antimicrobial surfaces to prevent healthcareassociated infections: a systematic review. J Hosp Infect 2016;92:7-13.

52. Humphreys H. Self-disinfecting and microbiocide-impregnated surfaces and fabrics: what potential in interrupting the spread of healthcare-associated infection? Clin Infect Dis 2014;58:848-53.

53. Adlhart C, Verran J, Azevedo NF, Olmez H, Keinänen-Toivola MM, Gouveia I, et al. Surface modifications for antimicrobial effects in the healthcare setting: a critical overview. J Hosp Infect 2018;99:239-49.

54. Querido MM, Aguiar L, Neves P, Pereira CC, Teixeira JP. Self-disinfecting surfaces and infection control. Colloids Surf B Biointerfaces 2019;178:8-21.

55. Tezel U, Pavlostathis SG. Quaternary ammonium disinfectants: microbial adaptation, degradation and ecology. Curr Opin Biotechnol 2015;33:296-304.

56. Gerba CP. Quaternary ammonium biocides: efficacy in application. Appl Environ Microbiol 2015;81:464-9.

57. Rutala WA, White MS, Gergen MF, Weber DJ. Bacterial contamination of keyboards: efficacy and functional impact of disinfectants. Infect Control Hosp Epidemiol 2006;27:372-7. 
58. Tamimi AH, Carlino S, Gerba CP. Long-term efficacy of a self-disinfecting coating in an intensive care unit. Am J Infect Control 2014;42:1178-81.

59. Rutala WA, Gergen MF, Sickbert-Bennett EE, Anderson DJ, Weber DJ. Sustained antimicrobial activity of a novel disinfectant against healthcare pathogens. Open Forum Infect Dis 2018;5(Suppl 1):55

60. Schmidt MG, Fairey SE, Attaway HH. In situ evaluation of a persistent disinfectant provides continuous decontamination within the clinical environment. Am J Infect Control 2019;47:732-4.

61. Weber DJ, Rutala WA. Use of metals as microbicides in the prevention of nosocomial infections. In: Rutala WA, editor. Chemical germicides in health care. Washington (DC): Association for Professionals in Infection Control and Epidemiology; 1994: 271-85.

62. Silvestry-Rodriguez N, Sicairos-Ruelas EE, Gerba CP, Bright KR. Silver as a disinfectant. Rev Environ Contam Toxicol 2007;191:23-45.

63. Percival SL, Bowler PG, Russell D. Bacterial resistance to silver in wound care. J Hosp Infect 2005;60:1-7.

64. Gerba CP, Sifuentes LY, Lopez GU, Abd-Elmaksoud S, Calabrese J, Tanner B. Widespectrum activity of a silver-impregnated fabric. Am J Infect Control 2016;44, 689-90.

65. Rutala WA, Weber DJ. New disinfection and sterilization methods. Emerg Infect Dis 2001:7:348-53.

66. Brady MJ, Lisay CM, Yurkovetskiy AV, Sawan SP. Persistent silver disinfectant for the environmental control of pathogenic bacteria. Am J Infect Control 2003;31: 208-14.

67. Bright KR, Gerba CP, Rusin PA. Rapid reduction of Staphylococcus aureus populations on stainless steel surfaces by zeolite ceramic coatings containing silver and zinc ions. J Hosp Infect 2002;52:307-9.

68. Cowan MM, Abshire KZ, Houk SL, Evans SM. Antimicrobial efficacy of a silverzeolite matrix coating on stainless steel. J Ind Microbiol Biotechnol 2003;30: 102-6.

69. Elguindi J, Hao X, Lin Y, Alwathnani HA, Wei G, Rensing C. Advantages and challenges of increased antimicrobial copper use and copper mining. Appl Microbiol Biotechnol 2011;91:237-49.

70. Grass G, Rensing C, Solioz M. Metallic copper as an antimicrobial surface. Appl Environ Microbiol 2011;77:1541-7.

71. O'Gorman J, Humphreys H. Application of copper to prevent and control infection. Where are we now? J Hosp Infect 2012;81:217-23.
72. Colin M, Klingelschmitt F, Charpentier E, Josse J, Kanagaratnam L, De Champs C, et al. Copper alloy touch surfaces in healthcare facilities: an effective solution to prevent bacterial spreading. Materials (Basel) 2018: 11:2479.

73. Vincent M, Hartemann P, Engels-Deutsch M. Antimicrobial applications of copper. Int J Hyg Environ Health 2016;219:585-91.

74. Weber DJ, Otter JA, Rutala WA. Can copper-coated surfaces prevent healthcareassociated infections? Infect Control Hosp Epidemiol 2017;38:772-7.

75. Vincent M, Duval RE, Hartemann P, Engels-Deutsch M. Contact killing and antimicrobial properties of copper. J Appl Microbiol 2018;124:1032-46.

76. Hinsa-Leasure SM, Nartey Q, Vaverka J, Schmidt MG. Copper alloy surfaces sustain terminal cleaning levels in a rural hospital. Am J Infect Control 2016;44:e195-203.

77. Schmidt MG, von Dessauer B, Benavente C, Benadof D, Cifuentes P, Elgueta A, et al Copper surfaces are associated with significantly lower concentrations of bacteria on selected surfaces within a pediatric intensive care unit. Am J Infect Control 2016:44:203-9.

78. von Dessauer B, Navarrete MS, Benadof D, Benavente C, Schmidt MG. Potential effectiveness of copper surfaces in reducing health care-associated infection rates in a pediatric intensive and intermediate care unit: a nonrandomized controlled trial. Am J Infect Control 2016;44:e133-9.

79. Sifri $C D$, Burke $G H$, Enfield KB. Reduced health care-associated infections in an acute care community hospital using a combination of self-disinfecting copper-impregnated composite hard surfaces and linens. Am J Infect Control 2016;44:1565-71.

80. Salgado CD, Sepkowitz KA, John JF, Cantey JR, Attaway HH, Freeman KD, et al. Copper surfaces reduce the rate of healthcare-acquired infections in the intensive care unit. Infect Control Hosp Epidemiol 2013;34:479-86.

81. Rivero P, Brenner P, Nercelles P. [Impact of copper in the reduction of hospitalacquired infections, mortality and antimicrobial costs in the Adult Intensive Care Unit]. Rev Chilena Infectol 2014:31:274-9.

82. Kim MH, Lee SG, Kim KS, Heo YJ, Oh JE, Jeong SJ. Environmental disinfection with photocatalyst as an adjunctive measure to control transmission of methicillinresistant Staphylococcus aureus: a prospective cohort study in a high-incidence setting. BMC Infect Dis 2018;18:610.

83. Pulliam JR. Lower infection rates after introduction of a photocatalytic surface coating. Am J Infect Control 2015;43:180-1.

84. de Jong B, Meeder AM, Koekkoek KWAC, Schouten MA, Westers P, van Zanten ARH. Pre-post evaluation of effects of a titanium dioxide coating on environmental contamination of an intensive care unit: the TITANIC study. J Hosp Infect 2018;99:256-62. 